\title{
Х. СИЛЬДВЭЭ
}

\section{ПОВТОРНЫЕ ИЗМЕРЕНИЯ СИЛЫ ТЯЖЕСТИ НА ТЕРРИТОРИИ ӘСТОНИИ}

Исследования вековых изменений силы тяжести на специальных полигонах были начаты в Советском Союзе в 1960-е годы (Буланже, 1965; Собакарь, 1968; Файтельсон, 1969 и др.).

На территории Эстонии в 1965-1966 гг. было заложено 11 гравиметрических пунктов для проведения повторных измерений силы тяжести в целях изучения их вековых изменений и выявления связи с современными вертикальными движениями земной коры. Гравиметрические пункты размещались равномерно по всей территории в среднем через $100 \kappa$. Они крепились бетонными монолитами (верхняя плита $0,8 \times 0,8$ м), опирающимися на коренные породы на глубине $1,2-1,5$ м. На каждом столбе было установлено по три бронзовых репера.

Реперы гравиметрических пунктов были привязаны нивелированием II класса к государственной нивелирной сети I и II класса. Использовались нивелиры Ni-004, H-1 и инварные рейки. Случайная ошибка нивелирования составляла $\pm 0,52$ мм и систематическая ошибка $\pm 0,16$ мм на один километр.

Измерения силы тяжести были проведены с помощью гравиметра Gs-11 методом одинарной и двойной петли со средней квадратичной ошибкой $\pm 0,06$ мәл. Гравиметр был эталонирован лабораторным методом и на местном гравиметрическом базисе (Козе-Ристи), который был создан Институтом физики Земли АН СССР в 1955 r. (Maasik и др., 1967).

В 1970-1972 гг. проводился второй этап повторных измерений. Заложенная в 1965-1966 гг. сеть гравиметрических пунктов была реконструирована и расширена 45 новыми пунктами. При их размещении учитывались следующие факторы: общий фон современных вертикальных движений и их дифференцированный характер, гравимагнитные аномалии, разновозрастные геологические структуры, особенности грунта и состояние дорожной сети. Гравиметрические пункты крепились бетонными монолитами $(0,5 \times 0,5 \times 0,8 \mathrm{~m})$, которые опирались на плиту $(0,7 \times$ $\times 0,7 \times 0,1 м$ ). На верхней плоскости каждого монолита было заложено по одному бронзовому реперу. Верхняя плита устанавливалась на глубине $0,2 м$ и основание столба на глубине $1,3-1,5 м$ от дневной поверхности.

Реперы гравиметрических пунктов были привязаны к государственной нивелирной сети по требованиям нивелирования II класса (нивелир Н-1 и 3-метровые инварные рейки). Длина нивелирных ходов не превышала 200-500 м, так как все гравиметрические пункты были заложены вблизи нивелирных реперов. 
Повторные измерения на заложенной в 1965-1966 гг. сети гравиметрических пунктов и привязка новых пунктов проводились гравиметрами типа ГАГ-2 № 21 и № 26 (выпуски 1969 и 1970 гг.). Контроль и юстирование гравиметров выполнялись согласно инструкции. Гравиметрические связи в цепочке звеньев полигона проводились по схеме $A-D-A-D$.

Гравиметры питались двумя аккумуляторами типа СТ-128. Они перевозились на специальной машине УАЗ-452 (ГС-5М) в транспортировочных ящиках в подушках из поропласта. Гравиметры работали в летнее время в основном на второй ступени термостатирования $\left(35,0^{\circ} \mathrm{C}\right)$. Наблюдения проводились при маленьких углах раствора.

У гравиметра ГАГ-2 № 21 средняя квадратичная ошибка определения $\Delta g$ составляла $\pm 0,020$ мәл и средний дрейф нуля $+0,09$ мгл/u, а у прибора № 26 соответственно $\pm 0,026$ мгл и $+0,12$ мгл/и. Средняя продолжительность одного рейса 2,5-3 ч. Время наблюдения на одном пункте с двумя приборами составляло около 20 мин. Расхождение между двумя полуприемами при углах раствора $2 v$ около $1^{\circ}$ допускалось в пределах 1 сек.

В 1970-1972 гг. с двумя гравиметрами проведено всего 275 двукратных определений $\Delta g$ со средней квадратичной ошибкой $\pm 0,03$ мәл (расстояние между пунктами около $35-40 \mathrm{\kappa m}$ ).

Сеть измерений 1970-1972 гг. состояла из шести полигонов со средней невязкой на полигоне $\sim 0,05$ мгл. Полигоны уравновешивались пропорционально времени проезда между пунктами.

К сети 1970-1972 гг. были привязаны также 15 исходных гравиметрических пунктов 1957 г. Величина ошибки определения $\Delta g$ в 1957 г. составляла $\pm 0,30$ мгл. В восьми случаях разница силы тяжести за $14-15$ лет равнялась или была больше двойной суммарной среднеквадратичной ошибки определения $\Delta g 1957$ и $1970-1972$ гг.

В результате повторных измерений составлены предварительные схемы вариаций силы тяжести на территории Эстонии относительно Таллина (рис. 1). Схемы изменения поля в периоды 1957-1966, 19661970/72 и 1957-1970/72 гг. сходны между собой. Из рис. 1 видно, что относительно Таллина выделяются две области, где наблюдается уменьшение силы тяжести: первая совпадает с минимумом гравитационного поля в Северной Әстонии, а вторая охватывает всю южную часть территории.

В 1970-1972 гг. проведены повторные измерения и на двух специальных трассах: Пыльтсамаа-Лелле и Роослепа-Тырва (рис. 2).

Специальный полигон повторных гравиметрических измерений, состоящий из восьми точек (рис. 2, I), создан на нивелирной трассе между Лелле и Пыльтсамаа, где геодезистами тогдашнего Института физики и астрономии АН ЭССР была выбрана испытательная трасса протяженностью 70 км для изучения дифференцированных движений земной коры. При выборе нивелирной трассы Пыльтсамаа-Лелле в качестве испытательного гравиметрического полигона исходили из следующих соображений:

1) трасса проходит перпендикулярно к наибольшим градиентам современных движений и хорошо изучена в отношении дифференцированных движений земной коры;

2) в своей средней части трасса пересекает предполагаемую тектонически активную полосу;

3) трасса Пыльтсамаа-Лелле пронивелирована в 1936, 1961, 1964, 1965, 1966, 1969 и 1972 годах (Желнин и др., 1972).

Гравиметрические пункты (среднее расстояние 8 км) расположены в непосредственной близости к следующим особенно надежным реперам: 


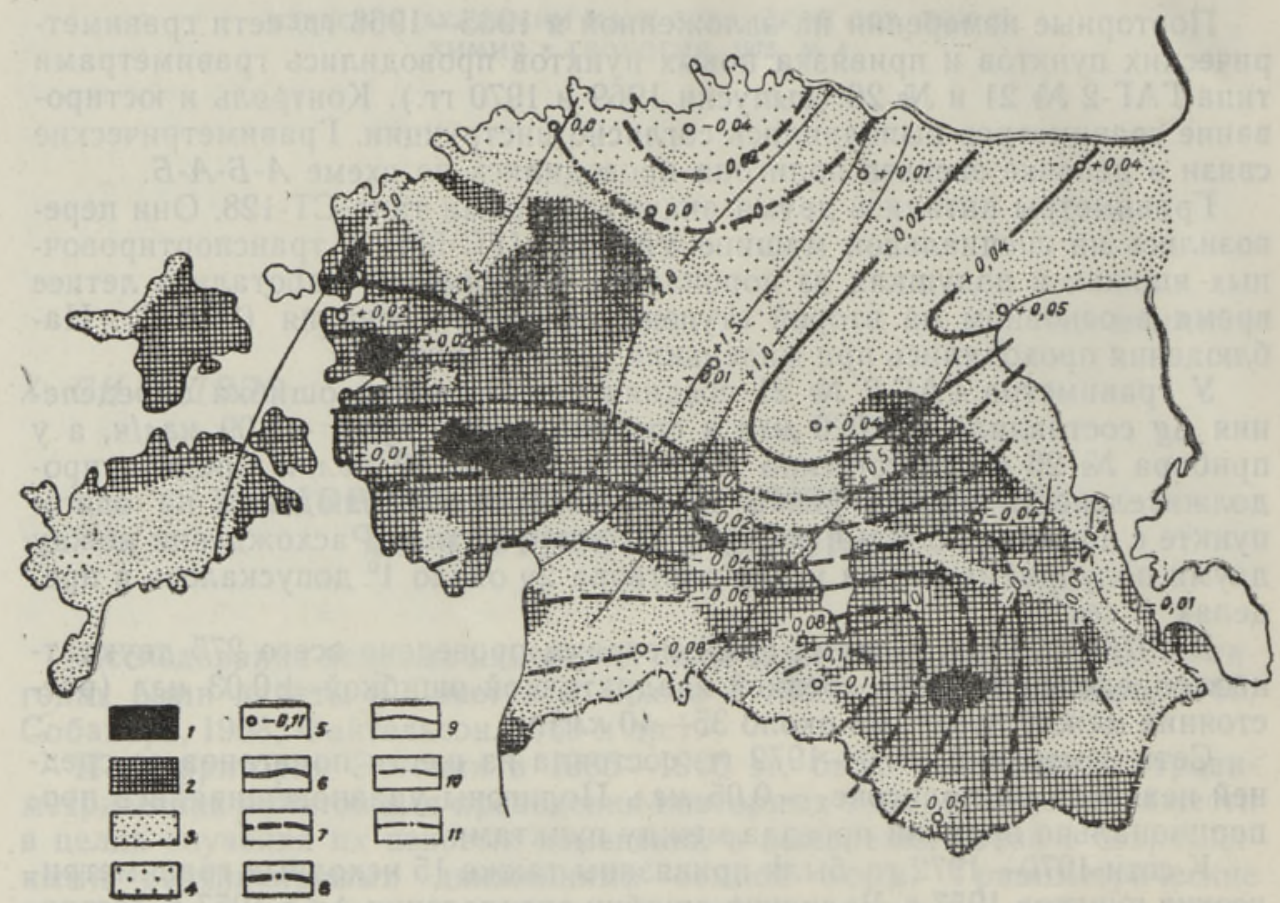

Рис. 1. Сопоставление гравитационного поля, изменений силы тяжести и вертикальных движений земной коры. Участки со значениями гравитационного поля: 1 - высокими, 2 - повышенными, 3 - пониженными, 4 - низкими; 5 - изменения силы тяжести $(\delta g)$ по наблюдениям 1957 и 1970-1972 гг., мел в год; изолинии $\delta g: 6$ - положительные, 7 - отрицательные, 8 - нулевая; изолинии современных вертикальных движений (Желнин, 1964), мм в год: 9 - положительные, 10 - отрицательные, 11 - нулевая.

грунтовому знаку на перекрестке шоссе Пыльтсамаа-Выхма-КолгаЯани и стенным реперам в церкви Пилиствере, в школе Кабала, в маслобойне Ойзу, в универмаге Тюри, в школах Колу и Кяру и в церкви Лелле. Из них гравиметрический пункт Тюри пришлось построить за пределами города для удобства измерений.

Испытательная трасса на участке Пыльтсамаа-Кабала проходит по интенсивным положительным магнитным аномалиям и пологим градиентам гравитационного поля. В окрестностях Ойзу-Локута она пересекает установленную по геофизическим данным региональную зону разломов кристаллического фундамента и на отрезке Локута-Лелле проходит вдоль градиента гравитационного и магнитного полей.

Повторные гравиметрические измерения на трассе ПыльтсамааЛелле проведены в 1970-1972 гг. почти в одинаковых условиях: в октябре при температуре от +10 до $+15^{\circ} \mathrm{C}$ с гравиметром типа ГАГ-2 № 21 на первой ступени термостатирования $\left(25,0^{\circ} \mathrm{C}\right)$ и с маленькими углами раствора. Расхождение между двумя полуприемами на пункте допускалось 1 сек. Средние квадратичные ошибки определения в 1970, 1971 и 1972 гг. были соответственно следующими: $\pm 0,04 ; \pm 0,03$ и $\pm 0,02$ мгл. При двух первых измерениях можно заметить накопление систематических ошибок. Для выяснения их причин анализировались средние ошибки определения отдельных $\Delta g$, градиенты температуры воздуха, градиенты атмосферного давления и фон микросейсмических помех, однако никаких корреляционных связей обнаружено не было.

На рис. 2, I наблюдается согласие между изменениями поля силы 
закладке пунктов Аудру, Раэ, Килинги-Нымме, Абья и Тырва учитывались дифференцированный характер современных вертикальных движений и зоны больших градиентов силы тяжести. Трасса Роослепа-Тырва пересекает интенсивные аномалии силы тяжести (Ригулди, Матсалу), причем интенсивные градиенты наблюдаются в окрестностях Калли, Аре, Килинги-Нымме, Абья и Тырва. Трасса проходит в основном по отрицательным или слабым положительным (Роослепа-Карузе-Абья) магнитным аномалиям. Измерения силы тяжести проводились в 19701972 гг со средней квадратичной ошибкой $\pm 0,03$ мгл. На рис. 2, II наблюдается согласие между кривыми $\delta g(3,4)$ с региональным полем силы тяжести (2) и современными вертикальными движениями (1). Все они возрастают в сторону Роослепа. Тенденция изменения $\delta g$ на обеих трассах согласуется со схемой региональных изменений силы тяжести по всей территории согласно данным 1957 и 1970-1972 гг. Вышесказанное позволяет предположить, что повторные измерения на травиметрических пунктах выявляют общую тенденцию вековых изменений силы тяжести.

Повторная сеть наблюдения для изучения вековых изменений травитационного поля на территории Әстонии еще редкая и не позволяет выявить общие закономерности между вековыми изменениями силы тяжести, гравитационным полем и современными движениями земной коры.

На основе детальных повторных измерений на трассах Пыльтсамаа-Лелле и Роослепа-Тырва можно сделать вывод, что на фоне регионального векового изменения поля силы тяжести (рис. 2; I, II, кривая 4) могут существовать более кратковременные и локальные изменения (рис. 2; I, II, кривая 3). Это указывает на то, что наблюдаемые изменения силы тяжести могут иметь различное происхождение, периоды и амплигуды.

Из приведенных измерений явствует, что вековые изменения силы тяжести в десятки раз больше, чем это могло быть вызвано современными вертикальными движениями на нашей территории.

Проведенные исследования об изменениях силы тяжести на территории Эстонии носят предварительный характер. В дальнейшем необходимо продолжать изучение закономерностей между вековыми изменениями силы тяжести, гравитационным полем, современными движениями земной коры и равновозрастными геологическими структурами. При этом существенной задачей является уменьшение инструментальных ошибок и уточнение методики.

\section{Л И Т Е Р А Т У Р А}

Буланже Ю. Д. 1965. Изменяется ли сила тяжести во времени? Земля и Вселенная, № 2 .

Ж ел ни н Г. А. 1964. Точность и возможности метода повторного нивелирования. В сб.: Современные и новейшие движения земной коры в Прибалтике. Вильнюс,

Желнин Г., В аллнер Л., Сильдвээ Х., Лумп Н. 1972. Изучение современных вертикальных движений земной поверхности на испытательной трассе Эстонской ССР. В сб.: Современные движения земной коры на геодинамических полигонах. Ташкент.

С об ак а р ь Г. Т. 1968. Қвазипериодические вариации силы тяжести Укранны. Докл. AH УССР, 179, № 9 .

$\Phi$ а й тельсон А. Ш. 1969. Вековые изменения силы тяжести в Арало-Каспийской области. Докл. АН СССР, 189, № 6.

M a a sik V., L u m p N., Sild ve e H. 1967. Raskusjõuvälja muutuste ja maakoore vertikaalliikumise vahelise korrelatsiooni uurimise võimalustest Eesti NSV territooriumil. ENSV TA Toimet., Keem. Geo!., 76, № 4. 


\section{RASKUSJOU KORDUSMOOTMISED EESTI NSV-s}

Raskusjoukiirenduse ajalise muutumise uurimiseks rajati 1965.-1966. a. üksteist gravimeetrilist punkti. Raskusjōu juurdekasvud määrati üheksa punkti vahel gravimeetrıga Gs-11 (keskmine ruutviga $\pm 0,06 \mathrm{mGl}$ ). Ajavahemikus 1970-1972 tihendati olemasolevat vörku ning rajati veel 45 gravimeetrilist punkti. Seejuures arvestati nüüdisaegsete maakoore vertikaalliikumiste diferentseeritud iseloomu, raskusjōu- ja magnetvälja anomaaliaid, maanteede olukorda, pinnasetingimusi jms. Raskusjôudu mõổdeti kahe $\Gamma A \Gamma-2$ tüüpi gravimeetriga (keskmine ruutviga $\pm 0,03 \mathrm{mGl}$ ). Mõōtmistulemused tasandati kuue kinnise polügooniga.

Kordusmõõtmiste põhjal koostati esialgne skeem raskusjõuvälja muutumisest Tallinna pōhipunkti suhtes (joon. 1). Mitmes kohas võib täheldada kooskōla raskusjōuvälja muutumise, välja intensiivsuse ja maakoore nüüdisaegsete vertikaalliikumiste vahel. Eriti ilmneb see Rooslepa-Tõrva profiilil (joon. 2).

\section{H. SILDVEE}

\section{ON REPEATED GRAVITY MEASUREMENTS ON ESTONIAN TERRITORY}

Between 1965 and 1966, eleven gravity stations were built on the territory of the Estonian SSR, especially for the study of the acceleration of gravity and its temporal development. Differences of gravity between the stations were measured with the Gs-11 gravimeter, with the standard deviation $\pm 0.06 \mathrm{mGal}$. From 1970 to 1972 the existing network was widened by another 45 stations.

Several factors were considered at the erection of the new stations: recent differentiated movements of the earth's crust, anomalies of gravity and magnet fields, condition of highways, the soil, etc. For gravity measurements, two gravimeters of the type GAG-2 were used, with the standard deviation $\pm 0,03 \mathrm{mGal}$. The results were adjusted to six closed polygons.

On the basis of the new measurements, a provisional scheme of the variations of gravity in respect to the Tallinn base station was drawn up (Fig. 1). In several parts of Estonia an agreement may be observed between the differences of the gravity field, intensity of the field and the recent vertical movements of the earth's crust. This is especially clearly revealed in the measurement sections between Rooslepa-Törva (Fig. 2). 